\title{
Trial of a family-based education program for heart failure patients in rural Thailand
}

Nittaya Srisuk ${ }^{1,2^{*}}$, Jan Cameron ${ }^{1}$, Chantal F Ski ${ }^{1}$ and David R Thompson ${ }^{1}$

\begin{abstract}
Background: Heart failure (HF) significantly impacts on the daily lives of patients and their carers. In Western society HF education programs have increased patient and carer knowledge and improved health-related quality of life. However, there is a paucity of such evidence in Asia. For example, to date no studies have been conducted in Thailand to investigate the potential benefits of a family-based education program on the health outcomes of HF patients and carers.
\end{abstract}

Methods: This randomised controlled trial will evaluate the effectiveness of an education program on knowledge, self-care and health-related quality of life of Thai HF patients and their carers. Assessments will be conducted at baseline, three and six months. Participants will be assigned by independent random allocation to an intervention (family-based education plus usual care) or a control (usual care) group. Analyses will be conducted on an intention-to-treat basis.

Discussion: This trial will be the first to evaluate the effectiveness of family-based education for HF patients and carers residing in rural Thailand. It attempts to advance understanding of family-based HF education and address the gap in service provision.

Trial registration: Thai Clinical Trial Registry TCTR20140506003

Keywords: Family, Education, Self-care, Health-related quality of life, Heart failure, Thailand

\section{Background}

Over 23 million people worldwide suffer from heart failure (HF) [1]. Already at epidemic proportions, this significant global public health problem is predicted to escalate exponentially over the next decade [1]. For example, currently in the United States HF affects over five million people [2] and it is expected that by 2030 eight million will be diagnosed with HF [3]. Heart failure is now one of the most common reasons for hospital admissions in older people, resulting in a substantial economic drain on healthcare resources [4].

One way to redress the burden of HF is through implementation of multidisciplinary chronic disease models of care that have been shown to yield significant benefits, compared with usual care, in reducing readmissions and associated costs and improving patient quality of life [5]. Identified as a key component of these programs

\footnotetext{
* Correspondence: S00140131@myacu.edu.au

${ }^{1}$ Centre for the Heart and Mind, Australian Catholic University, Melbourne, VIC, Australia

${ }^{2}$ Faculty of Nursing, Suratthani Rajabhat University, Suratthani, Thailand
}

is patient education specifically directed at promoting self-care behaviours [6]. Most studies investigating HF patient education have been conducted in Europe [7-10], Australia [11-13] and North America [14-17]. This leaves a significant knowledge gap regarding the efficacy of such programs in Asia, for example Thailand.

The Thai Acute Decompensated HEart Failure REgistry (Thai ADHERE) has recognised HF as a major cardiovascular health problem and economic burden [18]. Thai ADHERE epidemiological data were collected from 18 cardiovascular health centres across Thailand. Thai ADHERE found 2,041 HF admissions among 1,612 HF patients during 2006 to 2007. A large proportion of rehospitalisations were admitted via the emergency department (77\%), of which one quarter (25\%) required a critical care bed. The absence of HF education programs was identified as a significant factor leading to the high numbers of Thai HF readmissions [18]. Evidence presented from studies conducted in Western countries has 
demonstrated that many HF readmissions are preventable through patient education targeting self-care $[6,19]$.

Patient education aims to improve knowledge and skills in order to positively influence attitudes and behaviours, thereby resulting in improved health outcomes [20]. Knowledge can improve an individual's confidence and sense of control, and with respect to understanding the disease trajectory of HF, can motivate patients to adhere to treatment and lifestyle changes and necessary adaptations [21]. The evidence-base in support of patient education improving HF health outcomes is compelling $[5,6,22]$, and has resulted in the inclusion of educational strategies as a key non-pharmacological component within evidenced-based HF practice guidelines $[4,23,24]$.

The situation-specific theory of HF self-care provides a framework for understanding and evaluating the competencies of HF patients [25]. Self-care refers to a naturalistic decision-making process involving the choice of behaviours patients adopt in order to maintain physiological stability and responses executed when they occur [26]. Appropriate engagement in HF self-care has the potential to reduce HF readmissions and health care costs, and improve health-related quality of life [27]. In light of this, evidence has also revealed that patients with HF demonstrate difficulties in complying with the recommended self-care regimen [28]. Recently, and importantly, patient knowledge and social support from informal carers are fast being recognised as key to successful self-care [29-32].

The informal carer can be defined as a spouse/partner, family member, friend or neighbour who performs caring without pay, assisting the care recipient with daily activities and/or medicine administration [33]. The role of carers is crucial in HF self-care. A recent systematic review found that the social well-being of HF patients is strongly linked with carers' support in performing HF self-care [29]. Social support has been found to be a vital resource for patients with HF and used as part of their everyday coping strategies [32]. Patient health outcomes, including health-related quality of life (HRQoL), rehospitalisation, adherence to HF treatment, and optimal engagement in self-care, are strongly associated with the existence of carers [34]. International guidelines now specify that carers be included in the educational processes that promote HF self-care [35-37], though the number of intervention studies that have focused on informal carers of HF are limited [38].

Although the evidence is compelling as to the importance of patient education promoting self-care, most studies investigating patient education have been conducted in Europe, Australia and North America where the characteristics of the population and the culture are often quite different from that in Asia, including Thailand, and especially in rural communities. In Thailand only one published randomised trial of education (coaching by telephone) in HF has been conducted [39], and only two other published studies have explored the notion of education improving knowledge, self-care and HF symptoms [40,41]. However, limitations of these studies include the use of quasiexperimental designs, small samples, differing theoretical frameworks for developing the educational strategies, and varied settings - home-based to outpatient clinic settings for conducting them. Moreover, none of these studies included carers, or delivered the education program in the community, nor examined changes in HRQoL in both the patient and carer as an outcome of the education. In light of the incomplete body of knowledge regarding the effectiveness of an education-based intervention for HF patients and carers in Thailand, and the increasing prevalence of HF in Thailand, further research is warranted.

Cultural perspectives become paramount when adapting a Western-based intervention into an Asian country. For example, in Thailand the role of carer is crucial, and the Buddhist concept of karma strongly influences Thai people's beliefs and their way of thinking and living. Although demographic and socio-economic aspects have changed dramatically in Thailand over recent decades, family members remain the pillar of support for elderly people [42]. Living with older parents, showing respect and taking care of them are considered a normal way of family life and are highly valued in Thailand. Therefore, providing an education program that involves both the patient and carer has the potential to enhance the quality of life for the patient with HF, and for their supporting family [43].

\section{Aim}

The aim of this research is to develop and evaluate a family-based education program for HF patients and their carers residing in rural Thailand.

\section{Hypothesis}

We hypothesise that a family-based education program is effective in improving HF knowledge, self-care behaviour and HRQoL for patients, and perceived control, HF knowledge and HRQoL for their carers living in rural Thailand.

\section{Methods}

\section{Study design}

This is a prospective single-blind randomised controlled trial of family-based education versus usual care for HF patients and their partners residing in rural Thailand. Ethics approval has been obtained from the Human Research Ethics Committees of the Australian Catholic University and Chumphon Hospital and informed consent will be obtained from all participants prior to enrolment. The trial will be conducted in accordance with 
CONSORT (Consolidated Standards of Reporting Trials) guidelines ([44] See Figure 1).

The setting will be outpatient clinics at one provincial hospital and one community hospital in Chumphon province in the south of Thailand. These clinics were purposively selected on the basis that they are representative of HF patients and care in the rural community. Participants will be assigned by independent random allocation to an intervention (family-based education plus usual care) or a control (usual care) group.

\section{Participant eligibility}

Participants for this study will be a dyad consisting of a patient and their partner or family member that is identified as providing informal care. All participants will need to have sufficient comprehension to read Thai without the need for a translator. The patients will be aged 20 years or over, although with the increasing prevalence of HF in the elderly, it is envisaged that the majority will be above 50 years of age. The inclusion criteria for HF patients are: 1) a primary diagnosis of HF NYHA (New York Heart Association) class I to III confirmed by the treating doctor and determined by a history of typical signs and symptoms and physical examination [45] and, where possible, objective evidence of cardiac dysfunction on echocardiogram; 2) at least one family member residing with them; 3) contactable by telephone at home; and 4) a DVD player at home. The inclusion criteria for carers are: 1) living in the same household as the HF patient or someone of the patient's own choice; and 2) aged 20 years or over. Participants will be excluded if they reside in an urban area, have a documented history of dementia or severe psychiatric illness, are unable to continue to follow the protocol, and have severe symptoms indicative of acute heart failure

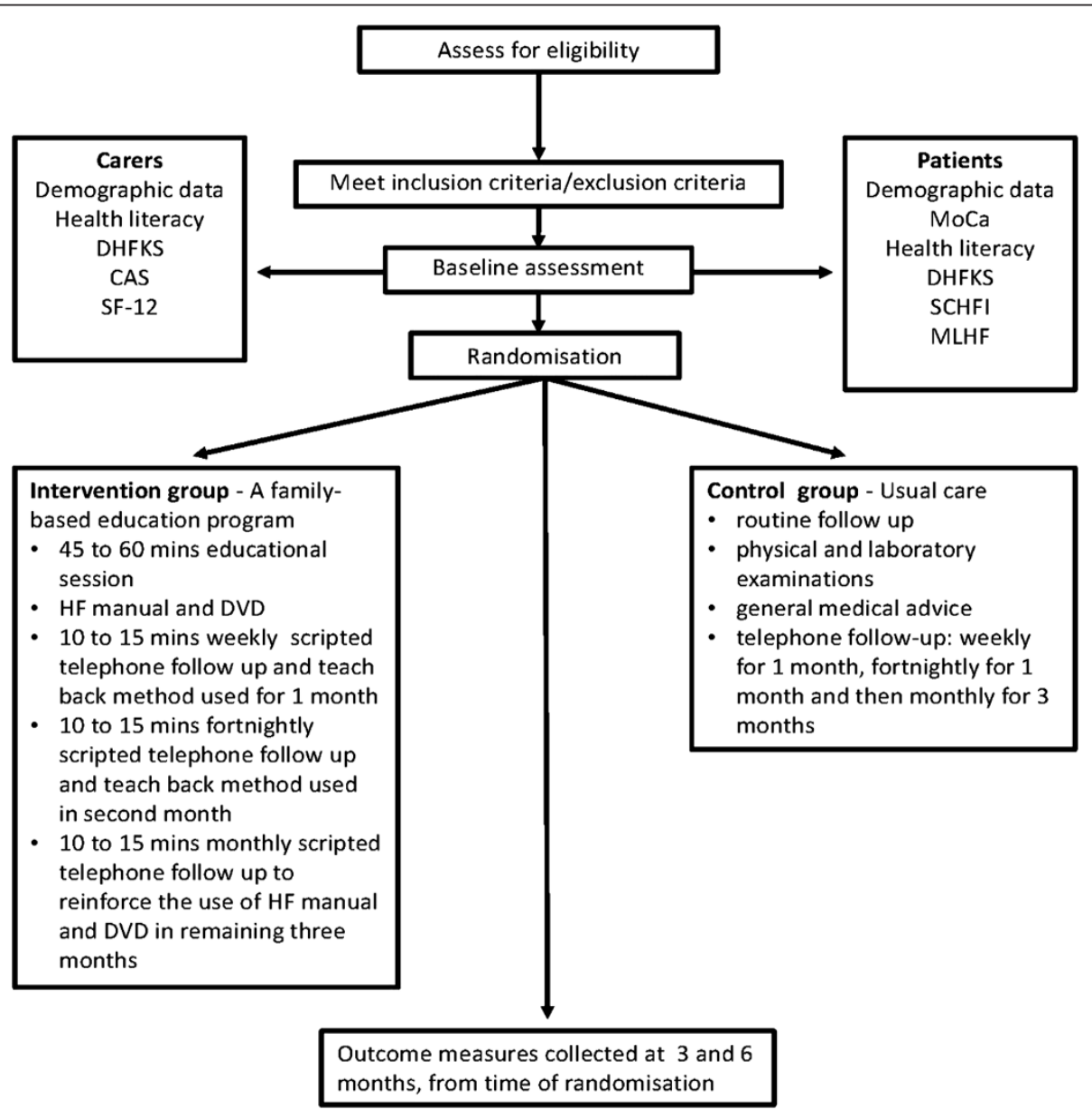

Primary outcome: Patient knowledge (DHFKS) and carer perceived control (CAS)

Secondary outcomes: Patient self-care (SCHFI) and HRQoL (MLHF). Carer knowledge (DHFKS) and HRQoL (SF-12) 
$[24,46]$ or complications from cardiac or disease or other life threatening comorbidities.

\section{Recruitment}

This trial will enroll a minimum of 100 dyads sourced from two rural hospitals in Thailand. Participants will be identified for enrolment by clinical staff based on inclusion criteria. Potential dyads will be approached at their regular outpatient appointment or contacted via telephone and verbally informed of the study. The dyads who agree to participate will receive a verbal and written explanation of the study by the investigator or the attending nurse, allowing them time to consider and freely participate.

\section{Randomisation}

The investigator will derive the random allocation from a computer-generated sequence of random numbers. Each dyad will be randomised at a 1:1 ratio in blocks of ten to either the control (usual care) or intervention (family-based education plus usual care) group. The random allocation will be sealed in an envelope and retained by technical staff at each hospital to give to the research assistants. Once participants have consented to the study and baseline data has been collected, the research assistant will open the sealed envelope indicating the group allocation. In this way, the research assistant collecting baseline data will be unaware of which group participants have been allocated to.

\section{Intervention}

\section{Development of the HF education DVD and manual}

A HF DVD and accompanying manual was developed by the principal investigator guided by adult learning theory [47] and studies that have investigated the individual learning needs of HF patients, especially in Asia [48-51]. Both the DVD and HF manual have been reviewed by a panel of HF experts in Australia and verified for content and cultural validity by a panel of HF experts in Thailand. The DVD and HF manual have been tested for readability and comprehensibility by three HF patients and carer dyads, who reported both resources to be helpful in gaining knowledge and selfcare skills as well as assisting in coping with HF.

The DVD contains nine chapters that explain key aspects in learning to live with and adjust to HF. Chapter headings are: 1) What is HF?; 2) How does HF make you feel?; 3) When you feel sick what should you do?; 4) How you can make your heart feel better?; 5) Your medicine; 6) Your health record; 7) Your HF action plan; 8) Tips for your family and friends; and 9) Conclusion. The DVD was developed in an easy and simple mode for patients and carers to readily absorb the information, using pictures that reflect the Thai cultural context. At the end of each chapter, a reflective question is asked to encourage the patient and their carer to interact and discuss openly potential issues (e.g. which of the symptoms is the hardest for me to manage?).

The written manual is based on the DVD chapters and combines information for both patient and their carers. The manual contains more detail than the DVD, including written material, pictures and health record forms. The HF manual is divided into easily recognisable, colour-coded chapters that correspond to the nine DVD chapters. Both patient and carer will be asked to read each chapter within the manual and also help each other to complete the reflective questions or activities at the end of each section.

\section{Intervention group}

Treatment fidelity will be used to guide the implementation of the educational program which consists of five processes including: design, training, delivery, receipt, and enactment $[52,53]$. The dyads in the intervention will receive their usual care plus a single individualised patient-carer education session. Education sessions will be conducted in the teaching room of the outpatient clinic. Dyads will receive the HF manual and a 45 to 60 minute education session focused on HF self-care. At the end of the session they will receive instructions about using the DVD and manual with their primary carer and/or family members. In addition, the intervention group will receive scripted telephone calls for $15 \mathrm{mi}-$ nutes per week in the first month, fortnightly in the second month, and once a month for the third to sixth month. The purpose of the telephone call is to reinforce, support and counsel each dyad about the HF information provided and assess any ongoing learning needs. The principal investigator will use the teach-back method [54] with each telephone call and give the dyad an opportunity to ask questions. The teach-back method is a technique used by educators to recall, deliver messages, encourage, and check for understanding, with participants asked to repeat the information that has been imparted to them [54]. This technique has been used to assess learning and promote self-care in patients with chronic conditions [54-56]. Specifically, in patients with HF, the teach-back method has been found to be an effective approach used in evaluating and educating patients' self-care abilities $[57,58]$.

\section{Control group}

The control group will receive usual care provided by a clinician that includes: routine follow-up, physical and laboratory examinations, and general medical advice. The carer of the HF patient will receive any additional information if requested. In addition, the control group will receive weekly telephone calls for the first month, fortnightly for the second month, and once a month for 
the third to sixth month. To reduce the potential of patient contact acting as a confounding variable, the control group will also receive matched telephone calls, although the content of these calls will differ to that of the intervention group by being of a generic nature. Thus the telephone calls for the control group will not contain information based on the family support intervention; instead they will discuss in general terms how the patient and carer are feeling. If the patient's condition has deteriorated significantly they will be advised to go and see their doctor. In consideration of the principle of fairness, at the end of the six month follow-up period participants in the control group will be offered a copy of the HF DVD and accompanying manual.

\section{Data collection}

Before randomisation all dyads will complete baseline questionnaires. Outcome measures will be collected at three and six months at the outpatient clinic or via telephone interview. Data will be collected by research assistants who are not aware of study group allocation. Questionnaires will take approximately 45 to 60 minutes to complete.

\section{Primary outcome measures}

The primary outcome will be HF knowledge as measured by the Dutch Heart Failure Knowledge Scale (DHFKS) in patients. The carers' primary outcome will be perceived control about managing their family member's HF as measured by the Control Attitudes Scale (CAS).

\section{Secondary outcome measure}

Secondary outcomes for patients will be self-care as measured by the Self-Care of HF Index (SCHFI) and HRQoL as measured by the Minnesota Living with HF (MLHF) questionnaire. For carers, secondary outcomes will be HF knowledge as measured by the Dutch Heart Failure Knowledge Scale (DHFKS) and HRQoL as measured by the Short-Form 12-item (SF-12) health survey.

\section{Participant descriptive data}

Participant clinical and socio-demographic characteristics will also be collected, including: number of social supports; education level; occupational status; health literacy (measured using a single question "How confident are you filling out medical forms by yourself?" [59]); cognitive assessment (measured using the Montreal Cognitive Assessment [60]); comorbid illness burden (measured using Charlson Comorbidity Index [61]); vital signs; cardiac- related history including cardiovascular risk factors and length of time living with HF; New York Heart Association functional classification [62]; and HF current treatment.

\section{Summary of outcome measure Knowledge}

The Dutch Heart Failure Knowledge Scale (DHFKS) [63] is a self-report questionnaire consisting of 15 multiple choice items related to: HF in general (4 items), HF treatment (6 items related to diet, fluid restrictions and activity), symptoms and symptom recognition (5 items). The scale has a minimum score of 0 (no correct answer) and a maximum score of 15 (all answers correct), higher scores indicate better knowledge. The tool developed in the Netherlands and tested on 902 HF patients, was found to be reliable (Cronbach's $\alpha$.62) and valid [58]. The scale has been shown to be sensitive in differentiating between patients who had and who had not received education and counselling $(p<.01)$ and has been widely used in clinical settings to evaluate patients' HF knowledge $[22,64,65]$.

\section{Self-care}

The Self-Care of Heart Failure Index (SCHFI) [66] is an instrument that measures HF self-care behaviours and skills through self-report. The SCHFI comprises 15items with a four-point Likert response scale. It contains three subscales: self-care maintenance, self-care management, and self-care confidence. Self-care maintenance measures symptom monitoring and compliance with HF treatment in order to prevent worsening symptoms such as checking ankles for swelling and eating a low salt diet. Self-care management measures the capability to recognise changes in HF symptoms, assess the meaning of the changes, and make a judgment on appropriate treatment actions. For example, if a patient experiences weight gain of more than $2 \mathrm{~kg}$ in two or three days, an appropriate action would be to take an extra diuretic. Self-care confidence measures perceived control to perform self-care in each phase such as how confident they feel in recognising symptom changes when they occur. Scores from each of the three self-care subscales are transformed to 100-point scales; higher scores reflect better self-care. Self-care management scores are only computed for those patients reporting HF symptoms of ankle swelling or trouble breathing in the previous three months [66]. The SCHFI was selected because it is a reliable measure of self-reported self-care skills and behaviours [66] and has been extensively validated among HF populations around the world. The SCHFI has also been reliably translated into Thai [67]. In the Thai context the tool was administered to $400 \mathrm{HF}$ patients and found to be reliable: Cronbach's alpha coefficient of 0.85 [67].

\section{Health-related quality of life}

The Minnesota Living with Heart Failure (MLHF) questionnaire (MLHF) [68] is a disease-specific measure of HF HRQoL assessing patients' perceptions as to the 
influence of HF on physical, socioeconomic, and psychological aspects of their life. The MLHF consists of 21 questions focused on patients' perceptions concerning the effects of HF on their physical functioning, such as shortness of breath, fatigue, and peripheral oedema and their emotional life such as memory loss, loss of selfcontrol, and side effects of HF treatment [68]. Patients respond to the 21 items using a 6 -point Likert scale $(0=$ no; $5=$ very much). The total score ranges from 0 to 105; a lower score reflects better HRQoL. Internal consistency reliability of the MLHF using Cronbach's alpha coefficient was .91 [69]. The Thai version has been used in $422 \mathrm{HF}$ patients, and in pilot testing in a sample of 30, had good reliability with a Cronbach's alpha coefficient of 0.94 [70].

The Short-Form 12-item (SF-12) health survey [71] is a generic measure of HRQoL that will be used in this study as a combination of generic and disease-specific measures has been recommended. The SF-12 [72] is a shortened version of the original SF-36 [73] and consists of 12 items with a 5 -point Likert scale $(1=$ all of the time, $5=$ none of the time). The 12 items include the self-assessment of health, physical functioning, physical role limitation, mental role limitation, social functioning, mental health, and pain. The summary score provides an indication of physical and emotional functioning, with higher scores indicating better HRQoL. The Thai version of the SF-12 has been used with 98 HF patients, reliability in this population was 0.83 [74].

\section{Perceived control about managing family member's heart problems}

The Control Attitudes Scale (CAS) family version will be used only for the carers of patients with HF in this study $[75,76]$. The CAS family version consists of eight items scale with a 5 -point response scale $(1=$ strongly disagree, to $5=$ strongly agree). The items address how much perceived control or how helpless individuals feel about managing their family member's heart problems. Higher scores indicate greater perceived control. Internal reliability of the CAS tested in 21 carers of patients with HF was 0.75 .

\section{Instrument translation}

There are three research tools which will be translated into Thai language: the brief screening questions for detecting in adequate health literacy, the DHFKS, and the CAS. The investigator will use the World Health Organisation [77] model process of translation and adaptation of instruments to guide the questionnaire translation.

\section{Data analyses and sample size calculation}

Data collected will be entered into the Statistical Package for the Social Sciences (SPSS Inc.). Descriptive statistics will be used to analyse demographic data. The sample size calculation is based on changes in HF knowledge. In a previous study investigating HF knowledge as the primary outcome [22]), a sample size of 50 per group and allowing for a $10 \%$ attrition rate, had adequate power $(0.80)$ with a two-sided 95\% significance to detect a difference of twopoints on the DHFKS between the intervention and control conditions in mean post-test versus pre-test changes on the DHFKS and 93\% power to detect clinically significant difference in MLHF scores of 6-points. For this study, assuming a medium effect size $(0.65)$ in the betweengroup differences on the DHFKS and allowing for a $20 \%$ attrition rate, the minimal sample size of 40 per group will have sufficient power (0.80). An independent $t$-test will be used to test the overall differences of the DFHKS, SCHFI, CAS, MLHF and SF-12 within the groups and between the control group and the intervention group at baseline and over three and six months. Two-way repeated measures analysis of variance (ANOVA) will be used to test the difference between groups and change overtime in each group of the main outcomes (DFHKS, SCHFI, CAS, MLHF and SF-12). Treatment failure and withdrawal will be considered on an intention-to-treat basis, with the aim of providing a more realistic estimate of the difference between the two groups.

\section{Process evaluation}

Ongoing monitoring of program activity in both the intervention and control group will be regularly conducted. Participants will be interviewed when the principal investigator performs a telephone follow-up. Participants in the control group will be asked how satisfied they are with regular telephone contact. The investigator will pilot test the DVD and HF manual in six HF patients and carers prior to implementation of intervention, to ensure their usability and refine if necessary. Participants in the intervention group will be asked how satisfied they are with the DVD and the HF manual and telephone follow-up. At the end of the program participant satisfaction will be measured using a visual analogue scale and participants will be invited to offer additional comments. Completion of activities in the HF manual will be assessed by viewing participants' HF manual at the six-month assessment. This process assessment is integral to identifying cultural and social facilitators of, and barriers to, the process of lifestyle behaviour change to improve HF risk as a result of this educational intervention.

\section{Discussion}

This trial will test the effectiveness of a family-based education program for HF patients and their carers residing in rural Thailand. Patient education is rapidly becoming recognised as a key component of HF management. Unfortunately, most trials of such programs have been undertaken in Western countries which have considerable 
differences to Asian countries in terms of, for example, patient characteristics, settings, interventions, and outcome measures. This is the first trial of such a program in rural Thailand taking into account cultural and societal factors.

The trial will not only provide evidence pertaining to the effectiveness of education programs for Thai HF patients, but it will be the first to include family members. We hypothesise that a family-based education program will improve HF knowledge, self-care and HRQoL in patients and carers in rural Thailand. This will be assessed via the implementation of a HF manual and DVD specifically developed to meet the knowledge requirement of $\mathrm{HF}$ patients and carers.

\footnotetext{
Abbreviations

HF: Heart Failure; Thai ADHERE: Thai Acute Decompensated HEart Failure REgistry; HRQoL: Health-Related Quality of Life; CONSORT: Consolidated Standards of Reporting Trials; NYHA: New York Heart Association; DVD: Digital Video Disc; DHFKS: Dutch Heart Failure Knowledge Scale; CAS: Control Attitudes Scale; SCHFI: Self-Care of HF Index; MLHF: Minnesota Living with Heart Failure questionnaire; SF-12: Short-Form 12-item health survey; ANOVA: ANalysis Of VAriance.
}

\section{Competing interests}

The authors declare that they have no competing interests.

\section{Authors' contributions}

NS, JC, CSF and DRT were involved in the conception and design of study and drafting of the manuscript. All authors read and approved the final manuscript.

\section{Acknowledgments}

This research is supported by the Faculty Research Student Support Scheme (FRSSS), Australian Catholic University, Australia and a Faculty of Nursing PhD scholarship from Suratthani Rajabhat University, Thailand.

Received: 8 July 2014 Accepted: 27 November 2014 Published: 3 December 2014

\section{References}

1. Bui $A B$, Horwich $T B$, Fonarow GC: Epidemiology and risk profile of heart failure. Nat Rev Cardiol 2011, 8(1):30-41.

2. Go AS, Mozaffarian D, Roger VL, Benjamin EJ, Berry JD, Blaha MJ, Dai S, Ford ES, Fox CS, Franco S, Fullerton HJ, Gillespie C, Hailpern SM, Heit JA, Howard VJ, Huffman MD, Judd SE, Kissela BM, Kittner SJ, Lackland DT, Lichtman JH, Lisabeth LD, Mackey RH, Magid DJ, Marcus GM, Marelli A, Matchar DB, McGuire DK, Mohler ER 3rd, American Heart Association Statistics Committee and Stroke Statistics Subcommittee, et al: Heart disease and stroke statistics-2014 update: a report from the American Heart Association. Circulation 2014, 129(3):e28-e292.

3. Heidenreich PA, Albert NM, Allen LA, Bluemke DA, Butler J, Fonarow GC, Ikonomidis JS, Khavjou O, Konstam MA, Maddox TM, Nichol G, Pham M, Piña IL, Trogdon JG: Forecasting the impact of heart failure in the United States: a policy statement from the American Heart Association. Circ Heart Fail 2013, 6(3):606-619.

4. Yancy CW, Jessup M, Bozkurt B, Butler J, Casey DE, Drazner MH, Fonarow GC, Gerac SA, Horwich T, Januzzi JL, Johnson MR, Kasper EK, Levy WC, Masoudi FA, McBride PE, McMurray JJ, Mitchell JE, Peterson PN, Riegel B, Sam F, Stevenson LW, Tang WH, Tsai EJ, Wilkoff BL: 2013 ACCF/AHA guideline for the management of heart failure: a report of the American College of Cardiology Foundation/American Heart Association task force on practice guidelines. J Am Coll Cardiol 2013, 62(16):e147-e239.

5. McAlister FA, Stewart S, Ferrua S, McMurray JJJV: Multidisciplinary strategies for the management of heart failure patients at high risk for admission: a systematic review of randomized trials. J Am Coll Cardiol 2004, 44(4):810-819.
6. Boren SA, Wakefield BJ, Gunlock TL, Wakefield DS: Heart failure self-management education: a systematic review of the evidence. Int J Evid Based Healthc 2009, 7(3):159-168.

7. Blue L, Lang E, McMurray JJV, Davie AP, McDonagh TA, Murdoch DR, Petrie MC, Connolly E, Norrie J, Round CE, Ford I, Morrison CE: Randomised controlled trial of specialist nurse intervention in heart failure. Br Med J 2001, 323(7315):715-718.

8. Cline CMJ, Israelsson BY, Willenheimer RB, Broms K, Erhardt LR: Cost effective management programme for heart failure reduces hospitalisation. Heart 1998, 80(5):442-446.

9. McDonald K, Ledwidge M, Cahill J, Quigley P, Maurer B, Travers B, Ryder M, Kieran E, Timmons L, Ryan E: Heart failure management: multidisciplinary care has intrinsic benefit above the optimization of medical care. J Card Fail 2002, 8(3):142-148.

10. Strömberg A, Mårtensson J, Fridlund B, Levin L-A, Karlsson J-E, Dahlstråm U: Nurse-led heart failure clinics improve survival and self-care behaviour in patients with heart failure results from a prospective, randomised trial. Eur Heart J 2003, 24(11):1014-1023.

11. Stewart S, Horowitz JD: Home-based intervention in congestive heart failure: long-term implications on readmission and survival. Circulation 2002, 105(24):2861-2866.

12. Stewart S, Marley JE, Horowitz JD: Effects of a multidisciplinary, home-based intervention on planned readmissions and survival among patients with chronic congestive heart failure: a randomised controlled study. Lancet 1999, 354(9184):1077-1083.

13. Stewart S, Pearson S, Horowitz JD: Effects of a home-based intervention among patients with congestive heart failure discharged from acute hospital care. Arch Intern Med 1998, 158(10):1067-1072.

14. Krumholz HM, Amatruda J, Smith GL, Mattera JA, Roumanis SA, Radford MJ, Crombie P, Vaccarino V: Randomized trial of an education and support intervention to prevent readmission of patients with heart failure. J Am Coll Cardiol 2002, 39(1):83-89.

15. Rich MW, Beckham V, Wittenberg C, Leven CL, Freedland KE: A multidisciplinary interventertion to prevent the readmission of elderly patients with congestive heart failure. N Engl J Med 1995, 2(333):1190-1195.

16. Rich MW, Vinson JM, Sperry JC, Shah AS, Spinner LR, Chung MK, Davila-Roman V: Prevention of readmission in elderly patients with congestive heart failure: results of a prospective randomized pilot study. J Gen Intern Med 1993, 8(11):585-590.

17. Riegel B, Carlson B, Kopp Z, LePetri B, Glaser D, Unnger A: Effect of a standardized nurse case-management telephone intervention on resource use in patients with chronic heart failure. Arch Intern Med 2002, 162(6):705-712.

18. Laothavorn P, Hengrussamee K, Kanjanavanit R, Moleerergpoom W, Laorakpongse D, Pachirat O, Boonyaratavej S, Sritara P: Thai Acute Decompensated Heart Failure Registry (Thai ADHERE). CVD Prev Control 2010, 5(3):89-95.

19. Ditewig JB, Blok H, Havers J, Veenendaal HV: Effectiveness of selfmanagement interventions on mortality, hospital readmissions, chronic heart failure hospitalization rate and quality of life in patients with chronic heart failure: a systematic review. Patient Educ Couns 2010, 78(3):297-315

20. Rankin SH, Stallings KD: Patient Education: Principles \& Practice. 4th edition. Philadelphia, PA: Lippincott, Williams and Wilkins; 2001.

21. Moser DK, Riegel B: Improving Outcomes in Heart Failure: An Interdisciplinary Approach. Gaithersburg, MD: Aspen; 2001.

22. Delaney C, Apostolidis B, Bartos S, Heather M, Smith L, Fortinsky R: A randomized trial of telemonitoring and self-care education in heart failure patients following home care discharge. Home Health Care Manag Pract 2013, 25(5):187-195.

23. Krum H, Jelinek MV, Stewart S, Sindone A, Atherton JJ, Hawkes AL: Guidelines for the prevention, detection and management of people with chronic heart failure in Australia 2006. Med J Aust 2006, 185(10):549-556.

24. McMurray JJV, Adamopoulos S, Anker SD, Auricchio A, Bo"hm M, Dickstein K, Falk V, Filippatos G, Fonseca C, Gomez-Sanchez MA, Jaarsma T, Køber L, Lip GY, Maggioni AP, Parkhomenko A, Pieske BM, Popescu BA, Rønnevik PK, Rutten FH, Schwitter J, Seferovic P, Stepinska J, Trindade PT, Voors AA, Zannad F, Zeiher A: ESC guidelines for the diagnosis and treatment of acute and chronic heart failure 2012. Eur Heart J 2012, 33(14):1787-1847

25. Riegel B, Dickson W: A situation-specific theory of heart failure self-care. J Cardiovasc Nurs 2008, 23(3):190-196. 
26. Riegel B, Carlson B, Moser DK, Sebern M, Hicks FD: Psychometric testing of the self-care of heart failure index. J Card Fail 2004, 10(4):350-360.

27. Barnason S, Zimmerman L, Young L: An integrative review of interventions promoting self-care of patients with heart failure. J Clin Nurs 2011, 21(3-4):448-475.

28. Riegel B, Moser DK, Anker SD, Appel L, Dunbar SB, Grady KL, Gurvitz MZ, Havranek EP, Lee CS, Lindenfeld J, Peterson PN, Pressler SJ, Schocken DD, Whellan DJ: State of the science: promoting self-care in persons with heart failure: a scientific statement from the American Heart Association. Circulation 2009, 120(12):1141-1163.

29. Buck HG, Harkness K, Wion R, Carroll SL, Cosman T, Kaasalainen S, Kryworuchko J, McGillion M, O'Keefe-McCarthy S, Sherifali D, Strachan PH, Arthur HM: Caregivers' contributions to heart failure self-care: a systematic review. Eur J Cardiovasc Nurs. in press.

30. Chen S, Yin Y, Krucoff MW: Effect of cardiac resynchronization therapy and implantable cardioverter defibrillator on quality of life in patients with heart failure: a meta-analysis. Europace 2012, 14(11):1602-1607.

31. Graven LJ, Grant JS: Social support and self-care behaviors in individuals with heart failure: an integrative review. Int J Nurs Stud 2014, 51(2):320-333.

32. Sacco SJ, Park CL, Suresh DP, Bliss D: Living with heart failure: psychosocial resources, meaning, gratitude and well-being. Heart Lung 2014, 43(3):213-218.

33. Sayers SL, Riegel B, Pawlowski S, Coyne JC, Samaha FF: Social support and self-care of patients with heart failure. Ann Behav Med 2008, 35(1):70-79.

34. Årestedt K, Saveman B-I, Johansson P, Blomqvist K: Social support and its association with health-related quality of life among older patients with chronic heart failure. Eur J Cardiovasc Nurs 2013, 12(1):69-77.

35. Lindenfeld J, Albert NM, Moser DK, Boehmer JP, Rogers JG, Collins SP, Starling RC, Ezekowitz JA, Stevenson WG, Givertz MM, Tang W, Teerlink JR, Walsh MN: HFSA 2010 comprehensive heart failure practice guideline. J Card Fail 2010, 16(6):e1-e194.

36. Arnold JMO, Howlett JG, Ducharme A, Ezekowitz JA, Gardner MJ, Giannetti N, Haddad H, Heckman GA, Isaac D, Jong P, Liu P, Mann E, McKelvie RS, Moe GW, Svendsen AM, Tsuyuki RT, O'Halloran K, Ross HJ, Sequeira EJ, White M: Canadian Cardiovascular Society Consensus Conference guidelines on heart failure - 2008 update: best practices for the transition of care of heart failure patients, and the recognition, investigation and treatment of cardiomyopathies. Can J Cardio/ 2008, 24(1):21-40.

37. Krum H, Jelinek MV, Stewart S, Sindone A, Atherton JJ, National Heart Foundation of Australia; Cardiac Society of Australia and New Zealand: 2011 update to National Heart Foundation of Australia and Cardiac Society of Australia and New Zealand guidelines for the prevention, detection and management of chronic heart failure in Australia 2006. MJA 2011, 194(8):405-409.

38. Strömberg A: The situation of caregivers in heart failure and their role in improving patient outcomes. Curr Heart Fail Rep 2013, 10(3):270-275.

39. Wongpiriyayothar A, Piamjariyakul U, Williams PD: Effects of patient teaching, educational materials, and coaching using telephone on dyspnea and physical functioning among persons with heart failure. Appl Nurs Res 2011, 24(4):e59-e66.

40. Kiatseesakul J, Momkong S, Pankakdee O, Choon-Ngarm T: The effect of a supportive educational program on knowledge self-care behavior, and the level of severity of heart failure. Thai J Cardio-Thoracic Nurs 2008, 19(2):23-39.

41. Rerkluenrit J, Khwanchai P, Soiorn T: Effects of a supportive educational program on functional status and self-care of persons with heart failure. Rama Nurs J 2012, 18(1):102-118.

42. Knodel J, Chayovan N: Intergenerational relationships and family care and support for Thai elderly. Ageing Int 2009, 35(1-4):15-27.

43. Thanakwang K: Social relationships influencing positive perceived health among Thai older persons: a secondary data analysis using the national elderly survey. Nurs Health Sci 2009, 11(2):144-149.

44. Boutron I, Moher D, Altman DG, Schulz KF, Ravaud P: Extending the CONSORT statement to randomized trials of nonpharmacologic treatment: explanation and elaboration. Ann Intern Med 2008, 148(4):295-309.

45. Ho KL, Anderson KM, Kannel WB, Grossman W, Levy D: Survival after the onset of congestive heart failure in Framingham heart study subjects. Circulation 1993, 88(1):107-115.

46. McKelvie RS, Moe GW, Ezekowitz JA, Heckman GA, Costigan J, Ducharme A, Estrella-Holder E, Giannetti N, Grzeslo A, Harkness K, Howlett JG, Kouz S,
Leblanc K, Mann E, Nigam A, O'Meara E, Rajda M, Steinhart B, Swiggum E, Le W, Zieroth S, Arnold JM, Ashton T, D'Astous M, Dorian P, Haddad H, Isaac DL, Leblanc MH, Liu P, Rao V, et al: The 2012 Canadian Cardiovascular Society heart failure management guidelines update: focus on acute and chronic heart failure. Can J Cardiol 2013, 29(2):168-181.

47. Knowles MS, Holton EF, Swanson RA: The Adult Learner: The Definitive Classic in Adult Education and Human Resource Development. London: Elsevier; 2005

48. Boyde M, Tuckett A, Peters R, Thompson DR, Turner C, Stewart S: Learning for heart failure patients (The L-HF patient study). J Clin Nurs 2009, 18(14):2030-2039.

49. Chiaranai C: A phenomenological study of day-to-day experiences of living with heart failure. J Cardiovasc Nurs 2014, 29(4):e9-e17.

50. Kato N, Kinugawa K, Sano M, Seki S, Kogure A, Kobukata K, Ochiai R, Wakita S, Kazuma K: Development of self-care educational material for patients with heart failure in Japan: a pilot study. Nurs Health Sci 2012, 14(2):156-164.

51. Yu M, Chair SY, Chan CE, Li X, Choi KC: Perceived learning needs of patients with heart failure in China: a cross-sectional questionnaire survey. Contemp Nurse 2012, 41(1):41-47.

52. Borrelli B, Sepinwall D, Ernst D, Bellg AJ, Czajkowski S, Breger R, DeFrancesco C, Levesque C, Sharp DL, Ogedegbe G, Resnick B, Orwig D: A new tool to assess treatment fidelity and evaluation of treatment fidelity across 10 years of health behavior research. J Consult Clin Psychol 2005, 73(5):852-860.

53. Borrelli B: The assessment, monitoring, and enhancement of treatment fidelity in public health clinical trials. J Public Health Dent 2011, 71(Suppl 1):S52-S63.

54. Schillinger D, Piette J, Grumbach G, Wang F, Wilson C, Daher K, Leong-Grotz K, Castro C, Blindman AB: Physician communication with diabetic patients who have low health literacy. Arch Intern Med 2003, 163(1):83-90.

55. Kripalani S, Bengtzen R, Henderson LE, Jacobson TA: Clinical research in low-literacy populations: using teachback to assess comprehension of informed consent and privacy information. IRB Ethics Human Res 2008, 30(2):13-19.

56. Wilson FL, Baker LM, Nordstrom CK, Legwand C: Using the teach-back and Orem's self-care deficit nursing theory to increase childhood immunization communication among low-income mothers. Issues Compr Pediatr Nurs 2008, 31(1):7-22.

57. White M, Garbez R, Carroll M, Brinker E, Howie-Esquivel J: Is "teach-back" associated with knowledge retention and hospital readmission in hospitalized heart failure patients? J Cardiovasc Nurs 2013, 28(2):137-146.

58. Mahramus T, Penoyer DA, Frewin S, Chamberlain L, Sole ML: Assessment of an educational intervention on nurses' knowledge and retention of heart failure self-care principles and the teach back method. Heart Lung 2014, 43(3):204-212.

59. Chew LD, Griffin JM, Partin MR, Noorbaloochi S, Grill JP, Snyder A, Bradley KA, Nugent SM, Baines AD, VanRyn M: Validation of screening questions for limited health literacy in a large VA outpatient population. J Gen Intern Med 2008, 23(5):561-566.

60. Nasreddine ZS, Phillips NA, Be'dirian V, Charbonneau S, Whitehead V Collin I, Cummings JL, Chertkow H: The Montreal Cognitive Assessment MoCA: A brief screening tool for mild cognitive impairment. J Am Geriatr Soc 2005, 53(4):695-699.

61. Charlson ME, Pompei P, Ales KL, Mackenzie CR: A new method of classifying prognostic comorbidity in longitudinal studies: development and validation. J Chronic Dis 1987, 40(5):373-383.

62. The Criteria Committee of the New York Heart Association: Diseases of the Heart and Blood Vessels: Nomenclature and Criteria for Diagnosis. 9th edition. Boston, MA: Little; Brown; 1994

63. van der Wal MH, Jaarsma T, Moser DK, van Veldhuisen DJ: Development and testing of the Dutch Heart Failure Knowledge Scale. Eur J Cardiovasc Nurs 2005, 4(4):273-277.

64. Boyde M, Song S, Peters R, Turner C, Thompson DR, Stewart S: Pilot testing of a self-care education intervention for patients with heart failure. Eur J Cardiovasc Nurs 2012, 12(1):39-46.

65. Boyne JJ, Vrijhoef HJ, Spreeuwenberg M, Weerd GD, Kragten J, Gorgels AP, TEHAF investigators: Effects of tailored telemonitoring on heart failure patients' knowledge, self-care, self-efficacy and adherence: a randomized controlled trial. Eur J Cardiovasc Nurs 2014, 13(3):243-252.

66. Riegel B, Lee CS, Dickson W, Carlson B: An update on the Self-Care of Heart Failure Index. J Cardiovasc Nurs 2009, 24(6):485-497. 
67. Suwanno J, Petpichetchian W, Riegel B, Issaramalai S-A: A model predicting health status of patients with heart failure. J Cardiovasc Nurs 2009, 24(2):118-126.

68. Rector TS, Cohn JN: Assessment of patient outcome with the Minnesota Living with Heart Failure questionnaire: reliability and validity during a randomized, double-blind, placebo-controlled trial of pimobendan. Am Heart J 1992, 124(4):1017-1025.

69. Heo S, Moser DK, Riegel B, Hall LA, Christman N: Testing the psychometric properties of the Minnesota Living with Heart Failure questionnaire. Nurs Res 2005, 54(4):265-272.

70. Krethong P, Jirapaet V, Jitpanya C, Sloan R: A causal model of health-related quality of life in Thai patients with heart-failure. J Nurs Scholarsh 2008, 40(3):254-260.

71. Strömberg A: The crucial role of patient education in heart failure. Eur J Heart Fail 2005, 7(3):363-369.

72. Ware JE, Kosinski M, Keller SK: A 12-item Short-Form health survey: construction of scales and preliminary tests of reliability and validity. Med Care 1996, 34(3):220-233.

73. McHorney CA, Ware JE, Lu R, Sherbourne CD: The MOS 36-item Short-Form health survey (SF-36): III tests of data quality, scaling, assumptions, and reliability across diverse patient group. Med Care 1994, 32(1):40-66.

74. Chiaranai C, Salyer J: Self-care and quality of life in patients with heart failure: do gender differences exist? Songkla Med J 2009, 27(6):451-463.

75. Moser DK, Dracup K: Psychosocial recovery from a cardiac event: the influence of perceived control. Heart Lung 1995, 24(4):273-280.

76. Moser DK, Dracup K: Impact of cardiopulmonary resuscitation training on perceived control in spouses of recovering cardiac patients. Res Nurs Health 2000, 23(4):270-278.

77. World Health Organisation: Process of translation and adaptation of instruments. [http://www.who.int/substance_abuse/research_tools/ translation/en/]

doi:10.1186/1471-2261-14-173

Cite this article as: Srisuk et al:: Trial of a family-based education program for heart failure patients in rural Thailand. BMC Cardiovascular Disorders 2014 14:173.

\section{Submit your next manuscript to BioMed Central and take full advantage of:}

- Convenient online submission

- Thorough peer review

- No space constraints or color figure charges

- Immediate publication on acceptance

- Inclusion in PubMed, CAS, Scopus and Google Scholar

- Research which is freely available for redistribution 